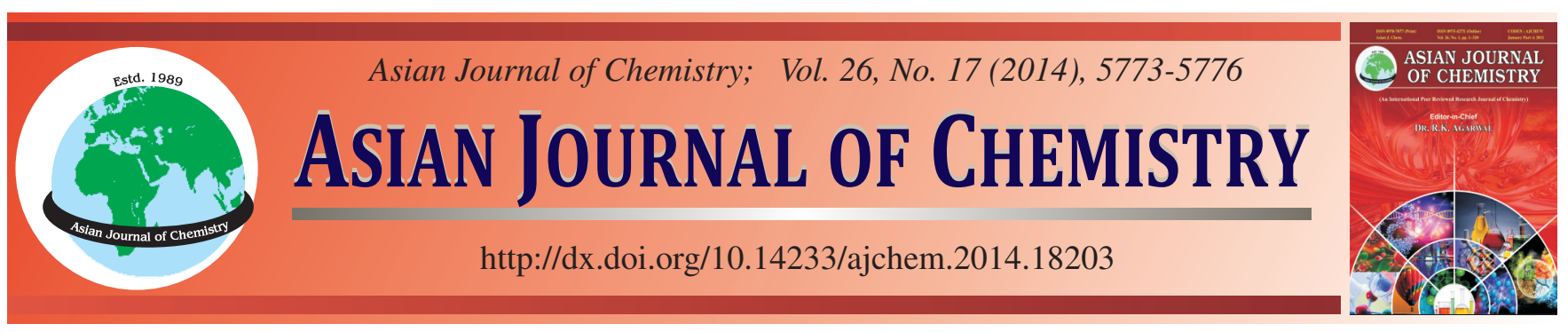

\title{
Background Estimation and Distribution of Anthropogenic Input of Cadmium in Arable Land Soil $\dagger$
}

DENGFENG WANG

Tropical Crops Genetic Resources Institute, Chinese Academy of Tropical Agriculture Sciences, Hainan Danzhou 571737, P.R. China

Corresponding author: E-mail: dfwang@vip.163.com

Obtaining accurate cadmium background concentrations in arable land soil is important because it can identify the anthropogenic Cd input distribution and realistically set the guiding level for remediation. In this study, four methods were applied, including the Iterative$2 \sigma$ technique, $95 \%$ upper confidence limit $\left(\mathrm{UCL}_{0.95}\right)$, accumulative frequency plot and GM+2GSD (geometric mean $+2 \times$ geometric standard) in order to estimate the Cd background concentrations in Hainan Island's arable land soil. In a comparative analysis, using the GM+2GSD method is ideal for estimating the background Cd concentrations since it does not consider the hypothetical distribution functions like $\mathrm{UCL}_{0.95}$. A concentration of $75 \mu \mathrm{g} \mathrm{kg}^{-1}$ was accepted as the $\mathrm{Cd}$ background concentration in arable land soils. The distribution of anthropogenic Cd inputs was obtained by subtracting the background concentrations from an existing spatial distribution of Cd. Rapid urbanization and excessive application of chemical fertilizers and pesticides have been attributed to the anthropogenic Cd input of Hainan's arable land soil.

Keywords: Cadmium, Background, Iterative-2 $\sigma$ technique, $95 \%$ upper confidence limit, Hainan.

\section{INTRODUCTION}

The background concentration of soil elements is its relative ratios of material composition and soil contents, in which are not influenced by human activities ${ }^{1-3}$. The analysis of background concentrations of soil elements is fundamental to soil geochemistry and food safety, particularly for areas that are strongly affected by human activities ${ }^{1,3,4}$. Identification of soil background concentrations is vital to a nation's agricultural production and food security. However, the background concentrations of soils must first be accurately profiled in order to differentiate the anthropogenic-sourced contaminants from the natural ones ${ }^{2,4,5}$. The known background concentrations of soil elements are applied to ascertain the degree of contamination in a certain region ${ }^{1,6}$.

The island of Hainan is a large producer of rice and tropical fruits. The content of soil heavy metals affects the quality of its agriculture products. As studied previously, the contents of soil $\mathrm{Hg}, \mathrm{Pb}, \mathrm{Cu}$ and $\mathrm{Zn}$ were acceptable and were not substantial environmental pollutants in the arable land of Hainan ${ }^{7,8}$. However, the $\mathrm{Cd}$ content exceeded the upper limit of the National Environment Quality Standard in the Sanya and Haikou districts of Hainan ${ }^{7-9}$. Cadmium is extremely toxic to plants and animals ${ }^{10}$. Cadmium contamination in arable land soils can reduce the yields and quality of rice crops ${ }^{11}$, which is a staple food for Hainan local residents. Cadmium contamination of arable land soil threatens the physical health of both the residents of Hainan and those dependent on its agricultural output. Therefore, studying the $\mathrm{Cd}$ distribution and the coverage of $\mathrm{Cd}$ enrichment in arable land soils is critical for preventing further pollution as well is necessary for the remediation of contaminated soils.

The distribution of anthropogenic $\mathrm{Cd}$ input can be obtained by subtracting the background concentration from known spatial distributions of soil Cd. Therefore, accurately estimating $\mathrm{Cd}$ background concentrations will be crucial. In this study, four approaches, the Iterative- $2 \sigma$ technique, $95 \%$ Upper confidence limit (UCL $\left.\mathrm{U}_{0.95}\right)$, Accumulative frequency plot and GM (geometric mean) + 2GSD ( $2 \times$ geometric standard), were applied to estimate the $\mathrm{Cd}$ background concentration in Hainan arable land soils and to identify the distribution of anthropogenic $\mathrm{Cd}$ input.

\section{EXPERIMENTAL}

Study area: Hainan Island, a producer of tropical agricultural products and winter vegetables, is one of the most important 
tropical islands of China. The arable land area is 0.73 million $\mathrm{hm}^{2}$. Hainan Island has the monsoon tropical climate, with an annual mean temperature of $22-26^{\circ} \mathrm{C}$. The annual mean precipitation varies from $1000 \mathrm{~mm}$ on the west coast to 2000 $\mathrm{mm}$ on the east coast.

Sampling and analytical work: Soil samples were collected from the upper $20 \mathrm{~cm}$ layer of each sample site located in the study area (Fig. 1). A total of 302 soil samples were collected. The soil samples were air-dried at room temperature, crushed and sieved to $<0.149 \mathrm{~mm}$.

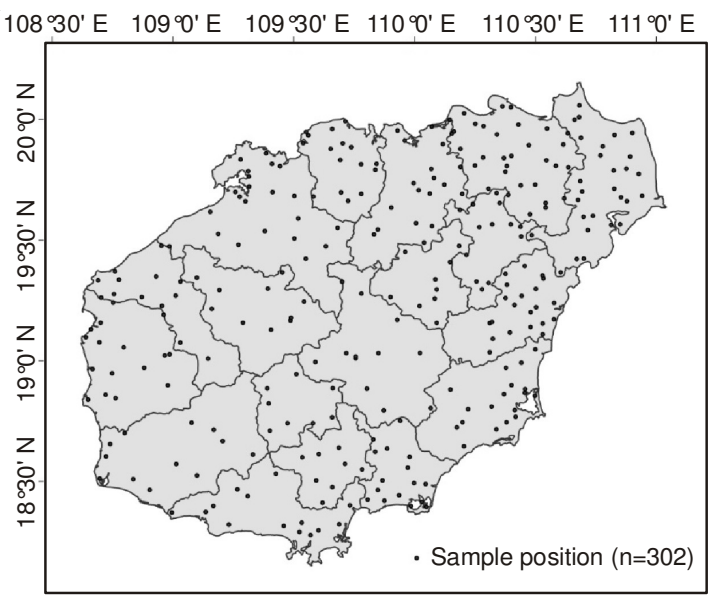

Fig. 1. Study area and sample position

The concentration $\mathrm{Cd}$ of the soil samples were measured by atomic absorption spectrometry (AAS). Quality control was assured by using duplicates and certified standard reference materials. The obtained results had good reproducibility and were in accordance with the certified concentrations.

Statistical analysis: All statistical analyses were performed using the SAS Systems for Windows 9.00. Using the spatial analysis tools of ArcGIS 10.0, the distribution of anthropogenic $\mathrm{Cd}$ input was obtained by subtracting background concentrations from the spatial distribution of soil $\mathrm{Cd}$ in the study area.

\section{RESULTS AND DISCUSSION}

Background estimation of Cd: The statistical characteristics indicated that the $\mathrm{Cd}$ distribution was steeper and more developed on the right side compared to the normal distribution (Fig. 2). The arithmetic mean (AM) of Cd concentration was $88 \mu \mathrm{g} \mathrm{kg}^{-1}$, which was above both the median and the geometric mean (GM). The Log-transformation significantly reduced the skewness and kurtosis of the data (Table-1).

Loska et al. ${ }^{12}$ suggested that the geometric mean and geometric standard deviation could be used to estimate the background when the data set does not conform to the normal distribution. The value of GM+2GSD was assumed as the background concentrations of $\mathrm{Cd}\left(75 \mu \mathrm{g} \mathrm{kg}^{-1}\right)$ in arable land soils.

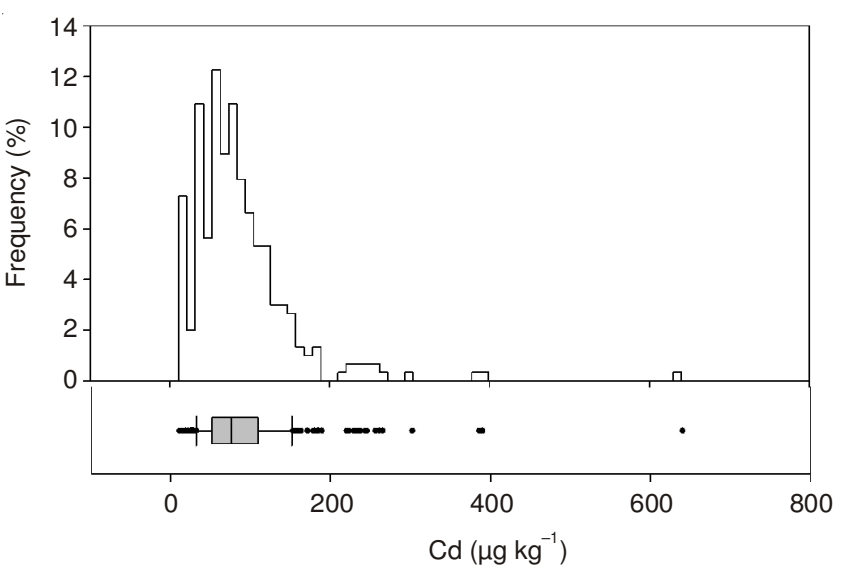

Fig. 2. Distribution of $\mathrm{Cd}$ in soil located in the study area

Since the data set in this study was approximately a normal distribution after the Log-transformation, the $95 \%$ upper confidence limit $\left(\mathrm{UCL}_{0.95}\right)$ of the mean was calculated using eqn. 1:

$$
\mathrm{UCL}_{1-\mathrm{a}}=\exp \left(\mathrm{x}_{\mathrm{y}}+0.5 \mathrm{~s}^{2}+\mathrm{s}^{2} \times \frac{\mathrm{H}_{1-\mathrm{a}}}{[\mathrm{n}-1]^{0.5}}\right)
$$

where $\mathrm{x}_{\mathrm{y}}$ is the arithmetic mean of the Ln-transformed data, $\mathrm{s}$ is the standard deviation of the Ln-transformed data, $\mathrm{n}$ is the number of samples and $\mathrm{H}_{1-\mathrm{a}}$ is the $\mathrm{H}$-statistic from the table provided by Gilbert for the $\mathrm{UCL}_{1-\mathrm{a}}$. The $\mathrm{UCL}_{1-\mathrm{a}}$ depends upon $\mathrm{x}_{\mathrm{y}}, \mathrm{n}$ and the chosen confidence limit $^{13}$. $\mathrm{UCL}_{1-\mathrm{a}}$ is dependent upon the number of samples, so the background estimation results are not reliable if there are too few samples. This study was conducted with 302 sampling points, so there are an appropriate number of samples to ensure that the method is a viable means on analysis. The $\mathrm{Cd}$ background content using results from $\mathrm{UCL}_{0.95}$ was $95 \mu \mathrm{g} \mathrm{kg}^{-1}$.

The accumulative frequency analysis method is a tool for geology-statistical analysis. In statistical applications, the cumulative distribution is usually plotted on normal probability paper, primarily to estimate percentiles and to testify the assumption of normality of the data set. As the data set was normally distributed, the cumulative distribution was linearly plotted on normal probability paper. The significant deviations from the normal distribution indicate a statistically significant aberration in the distribution of the $\mathrm{Cd}$ concentration in this study (Fig. 3). This curve consisted of two segments connected by a steeply sloping segment in the central part of the curve. Tenant and White reported that the probability plots of geochemical data frequently consist of two straight-line segments, which they interpreted as a representation of different geochemical populations ${ }^{14}$. Fleischhauer and Korte indicated that the background's upper limit could be identified as the inflection point on the probability graph, that is, where the concavity of the curve changes from downwards to upwards ${ }^{15}$. By dividing the natural soil background using the

TABLE-1

STATISTICAL CHARACTERISTICS OF Cd CONTENT IN SOIL OF THIS STUDY $\left(\mu \mathrm{g} \mathrm{kg}^{-1}\right)$

\begin{tabular}{cccccccccc}
\hline & \multirow{2}{*}{$\mathrm{N}$} & \multirow{2}{*}{ Range } & \multirow{2}{*}{ Median } & \multirow{2}{*}{$\mathrm{AM} \pm \mathrm{ASD}^{\mathrm{a}}$} & \multirow{2}{*}{$\mathrm{GM} \pm \mathrm{GSD}^{\mathrm{b}}$} & \multicolumn{2}{c}{ Origin data } & \multicolumn{2}{c}{ Log-transformed data } \\
\cline { 6 - 10 } & & & & & & & & & \\
$\mathrm{Cd}$ & 302 & $11-640$ & 76 & $88 \pm 64$ & $71 \pm 2$ & 3.3 & 20.3 & -0.4 & 0.8 \\
\hline
\end{tabular}

${ }^{\mathrm{a}} \mathrm{AM} \pm \mathrm{ASD}$ : Arithmetic mean \pm arithmetic standard deviation, ${ }^{\mathrm{b}} \mathrm{GM} \pm \mathrm{GSD}$ : Geometric mean \pm Geometric standard deviation 


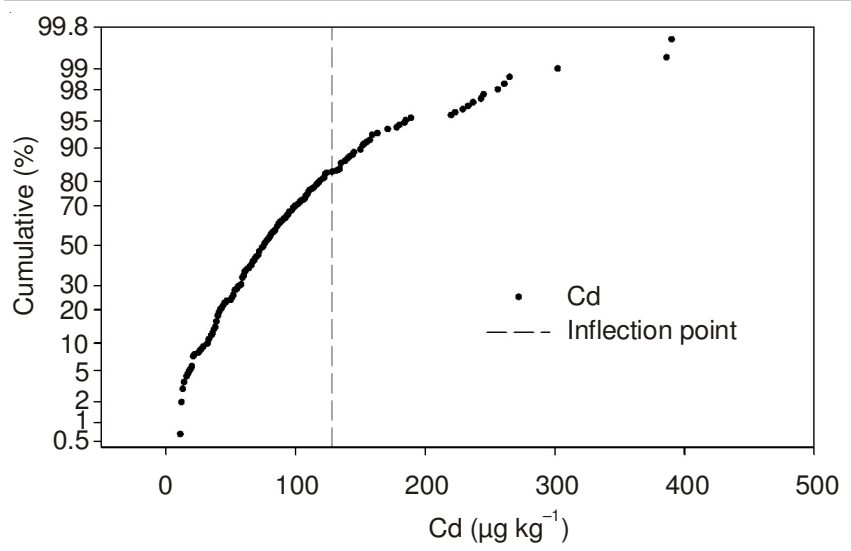

Fig. 3. Accumulative frequency plot of Cd contents in soil in the study area

inflection point, the mean and standard deviation of data under the inflection point can be used to determine the background values of soil elements ${ }^{16-18}$.

When using this method to establish the background concentrations of soil elements, the most difficult part is determining the inflection point of the accumulative frequency plot. The samples exhibiting the natural background values of soils are separated, especially when the sample concentrations are representative of both natural soil background and polluted sample concentrations. If only the accumulative frequency curves are applied for determining the inflection points, inaccurate background values will be generated ${ }^{19}$. Consequentially, the sample points representative of soil natural background were identified through determining the background values of soil elements by using probability graphs combined with statistical analysis (skewness) in order to avoid errors that are caused by sole dependence on accumulative frequency plots $^{15}$. The background data of the sites should appear to be normally or approximately normally distributed. These analyses generate a standardized estimate of the inflection point, the upper limit of the background, on the basis of skewness. Since the normally distributed data set has a skewness of zero, the graphical inflection point can be interpreted as a skewness value close to zero.

Seen from the accumulative frequency plot, the inflection point was distributed in the 125-130 range (Fig. 3). By calculating the skewness of sampling points below the inflection point value, the $\mathrm{Cd}$ content of the sampling point, in which the skewness was the nearest to zero, was found to be $128 \mu \mathrm{g} \mathrm{kg}^{-1}$. The skewness of the background data set was -0.037 if below the inflection point in the accumulative frequency plot. The Cd background could be calculated by the mean and standard deviation of background data set and was found to be $127 \mu \mathrm{g} \mathrm{kg}^{-1}$.

The right-side developed data set tended towards higher values, which indicated that outliers in the soil $\mathrm{Cd}$ concentrations should not be used as background concentration values. Therefore, statistical deviants of the original data set were omitted for the iterative $2-\sigma$ technique in estimation of the background concentration. This technique was used to confine the background to a normal range ${ }^{18}$. Arithmetic mean (AM) and arithmetic standard deviation (ASD) were calculated for the original data set. The values out of the $\mathrm{AM} \pm 2 \mathrm{ASD}$ interval range were omitted. Omissions were repeated until the remaining values fell within the range of $\mathrm{AM} \pm 2 \mathrm{ASD}$. Now, the remaining data set accurately reflected the background and more closely resembled the normal distribution. In this study, the upper limit of the $2-\sigma$ technique for $\mathrm{Cd}$ content was $128 \mu \mathrm{g} \mathrm{kg}^{-1}$.

As shown in Fig. 4, the results of background contents of $\mathrm{Cd}$ in the four methods varied. The background content obtained by $\mathrm{GM}+2 \mathrm{GSD}$ and $\mathrm{UCL}_{0.95}$ were consistent, while the results of the Iterative $2-\sigma$ technique and the accumulative frequency plot were similar to one another. The differences between results arose because the $\mathrm{GM}+2 \mathrm{GSD}$ and $\mathrm{UCL}_{0.95}$ represent the average background concentration of soil $\mathrm{Cd}$; however, the Iterative $2-\sigma$ technique and the accumulative frequency plot represent the upper limits of concentration of soil $\mathrm{Cd}$ in the study area and these samples are disposed of if they are affected by human activity.

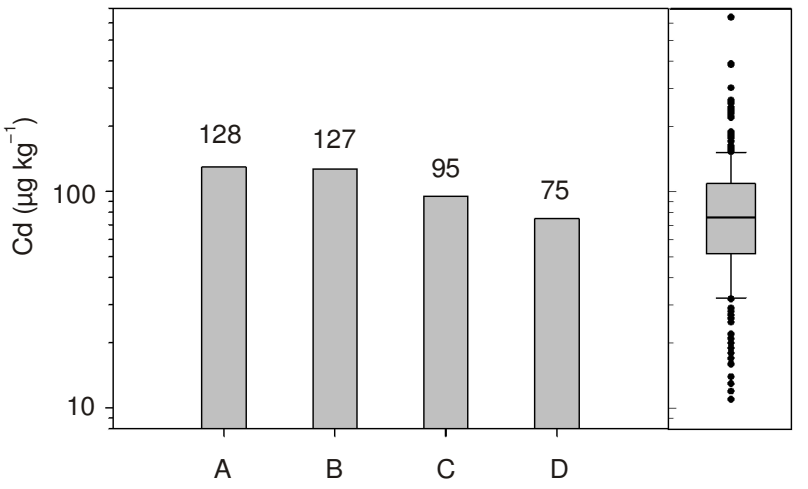

Fig. 4. Results of Cd background concentrations as estimated by various methods. A: Iterative- $2 \sigma$ technique; B: accumulative frequency plot; C: $\mathrm{UCL}_{0.95} ; \mathrm{D}: \mathrm{GM}+2 \mathrm{GSD}$

Lower values were considered acceptable for the background concentration of $\mathrm{Cd}$ in arable land soils because the effects of anthropogenic $\mathrm{Cd}$ inputs may be neglected in the case of an over-estimation of the $\mathrm{Cd}$ background concentration. Therefore, the result of GM+2GSD, $75 \mu \mathrm{g} \mathrm{kg}^{-1}$, was accepted as the background concentration of $\mathrm{Cd}$ in Hainan Island's arable land soil.

Distribution of anthropogenic Cd input: The distribution of anthropogenic $\mathrm{Cd}$ input (Cd surplus) indicated that $53.5 \%$ of the total area was higher than the Cd background concentration (Fig. 5). The highest anthropogenic Cd input area was distributed in the Haikou district, the Hainan Island's largest urban area. Unreasonable urban expansion, industrial emissions, construction practices and transportation development are contributing causes of the enrichment of heavy metals in suburban arable land soils.

Additionally, as previous researchers have indicated, heavy metals are inclined to accumulate in urban soils ${ }^{5,20,21}$. Accordingly, the enrichment of heavy metals in the Haikou district coincided with the development of the Hainan tourism industry and the establishment of Haikou as an economic, political and cultural epicenter of the island ${ }^{21}$.

Deposition of $\mathrm{Cd}$ is also the result of the application of chemical fertilizers and pesticide ${ }^{7,21}$. Due to the decrease in soil fertility in Hainan Island ${ }^{22,23}$, the consumption volumes of chemical fertilizers and pesticides has increased significantly 


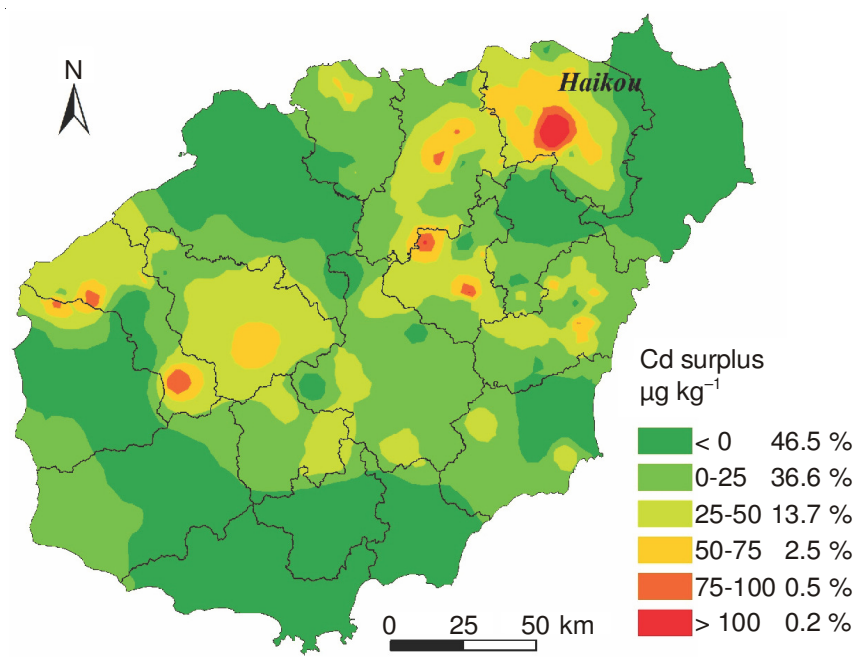

Fig. 5. Results of Cd background concentrations as estimated by various methods

in recent years, from $4.04 \times 10^{5}$ tons in 1995 , to $8.63 \times 10^{5}$ tons in 2006 and $1.18 \times 10^{6}$ tons in $2010^{24}$.

\section{Conclusion}

Results indicate that certain differences exist in the background contents of $\mathrm{Cd}$ in Hainan arable land soils. These differences were characterized using four techniques: the Iterative- $2 \sigma$ technique, $95 \%$ upper confidence limit, accumulative frequency plot and GM+2GSD. The lower value of 75 $\mu \mathrm{g} \mathrm{kg}{ }^{-1}$ was accepted as the background concentration of $\mathrm{Cd}$ in arable land soils in the study area. The distribution of anthropogenic $\mathrm{Cd}$ inputs was obtained by subtracting the background concentrations from the existent spatial distribution of $\mathrm{Cd}$ in the study area. The serious anthropogenic $\mathrm{Cd}$ input was a result of rapid urbanization, while the regional anthropogenic $\mathrm{Cd}$ inputs were a product of excessive application of chemical fertilizers and pesticides in arable land.

\section{ACKNOWLEDGEMENTS}

This research was supported by the Hainan Provincial Natural Science Foundation of China (312054) and the National Nonprofit Institute Research Grant of CATAS-TCGRI (1630032014035).

\section{REFERENCES}

1. A. Fairbrother, R. Wenstel, K. Sappington and W. Wood, Ecotoxicol. Environ. Saf., 68, 145 (2007).

2. Z.L. Xia, S.Z. Li, T.F. Li and Y. Ba, Background Values of Soil Elements and Research Method, China Meteorological Press, Beijing (1987).

3. J. Sakalys, K. Kvietkus, J. Sucharová, I. Suchara and D. Valiulis, Chemosphere, 76, 91 (2009).

4. X. Zhou and B.C. Xia, J. Hazard. Mater, 180, 542 (2010).

5. T.B. Chen, Y.M. Zheng, H. Chen and G.D. Zheng, Environ. Sci., 25, 117 (2004)

6. R.P. Breckenridge and A.B. Crockett, Environ. Monit. Assess., 51, 621 (1998).

7. F.Y. Li, X.M. Li, P.F. Wu, L.Y. Chen, B. Guo and Z.P. Qi, Soils, 41, 49 (2009).

8. F.Y. Li, X.M. Li, P.F. Wu, X. Zhao, D.M. Zhang and Z.P. Qi, J. Agric. Sci. Technol., 11, 133 (2009).

9. X.-N. Li, H.-L. Song, W. Li, X.-W. Lu and O. Nishimura, Chinese J. Ecol., 36, 382 (2010).

10. A. Kabata-Pendias and H. Pendias, Trace Elements in Soils and Plants, CRC Press, Boca Raton, FL (2001).

11. X. Zhao, F.Y. Li, D.M. Zhang and Z.P. Qi, J. Agro-Environ. Sci., 28, 2236 (2009).

12. K. Loska, D. Wiechula, I. Korus and J. Pelczar, Bull. Environ. Contam. Toxicol., 74, 732 (2005).

13. R.O. Gilbert, Statistical Methods for Environmental Pollution Monitoring, Van Nostrand Reinhold Co., New York (1987).

14. C.B. Tennant and M.L. White, Econ. Geol., 54, 1281 (1959).

15. H.L. Fleischhauer and N. Korte, Environ. Manage., 14, 95 (1990).

16. C. Lepeltier, Econ. Geol., 64, 538 (1969).

17. F.J. Tobías, J. Bech and P.S. Algarra, Sci. Total Environ., 206, 255 (1997).

18. J. Matschullat, R. Ottenstein and C. Reimann, Environ. Geology, 39, 990 (2000).

19. A. Singh, A.K. Singh and G. Flatman, Math. Geol., 26, 361 (1994).

20. T.B. Chen, M.H. Huang, H.Z. Huang and H.Y. Zhou, Acta Geogr. Sin., 52, 228 (1997).

21. X.Y. Li, T.B. Chen, M. Lei, Q.J. Guo, B. Song, G.D. Zhou and Y.F. Xie, Acta Sci. Circumstant., 30, 2285 (2010).

22. D.F. Wang, Z.Y. Wei, L.W. Lv and Z.P. Qi, Chinese J. Tropical Crops, 33, 1966 (2012).

23. D.F. Wang, Z.Y. Wei, L.W. Lv, Y. Fang and Z.P. Qi, Tropical Geography, 32, 593 (2012).

24. Z.P. Qi, Z.Y. Wei, F.Y. Li and S.M. Tang, Chinese J. Soil Sci., 40, 1292 (2009). 